\title{
High-Density Lipoprotein Cholesterol and the Risk of First Ischemic Stroke in a Chinese Hypertensive Population
}

\author{
Yue Zhang,' Jingyi Li, ${ }^{2}$ \\ Chengzhang Liu, ${ }^{3}$ Hongxiang Yu, \\ Chen Chen,' Chonglei Bi, ${ }^{4}$ \\ Chongqian Fang, ${ }^{4} \mathrm{Hai} \mathrm{Ma},{ }^{5}$ \\ Aimin $\mathrm{Li}^{6}{ }^{6}$ Qing Dong, ${ }^{7}$ \\ Lishun Liu, ${ }^{8}$ Binyan Wang, ${ }^{3}$ \\ Xiao Huang, (iD) Xiaoshu Cheng, ${ }^{9}$ \\ Pierre Zalloua, (iD ${ }^{10}$ Xiping Xu, ${ }^{1 i}$ \\ Yong Huo, (D) ${ }^{12}$ Gang Li (DD'
}

'Department of Neurology, East Hospital, Tongji University School of Medicine, Shanghai, People's Republic of China; ${ }^{2}$ State Key

Laboratory of Natural Medicines, Research

Center of Biostatistics and Computational

Pharmacy, China Pharmaceutical University,

Nanjing, People's Republic of China; ${ }^{3}$ Shenzhen

Evergreen Medical Institute, Guangzhou,

People's Republic of China; ${ }^{4}$ People's Hospital

of Rongcheng, Rongcheng, Shandong, People's

Republic of China; ${ }^{5} \mathrm{Health}$ and Family Planning

Commission, Rongcheng, Shandong, People's

Republic of China; ${ }^{6}$ Department of

Neurosurgery, Lianyungang Clinical College of

Nanjing Medical University, Lianyungang,

People's Republic of China; ${ }^{7}$ Lianyungang

Health Committee, Lianyungang, Jiangsu,

People's Republic of China; ${ }^{8}$ Beijing Advanced Innovation Center for Food Nutrition and

Human Health, College of Food Science and

Nutritional Engineering, China Agricultural

University, Beijing, People's Republic of China;

${ }^{9}$ Department of Cardiovascular Medicine, The

Second Affiliated Hospital of Nanchang

University, Nanchang, People's Republic of

China; ${ }^{10}$ School of Medicine, Lebanese American University, Beirut, Lebanon; ' 'Division of

Nephrology, Nanfang Hospital, Southern Medical University; National Clinical Research Center for Kidney Disease; State Key Laboratory of Organ

Failure Research; Guangdong Provincial Institute of Nephrology, Guangzhou, People's Republic of

China; ${ }^{12}$ Department of Cardiology, Peking

University First Hospital, Beijing, People's Republic of China

Correspondence: Gang $\mathrm{Li}$

1800 Yuntai Road, Shanghai, 200I23,

People's Republic of China

Tel +86-2I-388045 I8-22I 07

Fax +86-2I-58798999

Email ligang@tongji.edu.cn
Background and Purpose: Elevated high-density lipoprotein cholesterol (HDL-C) levels have displayed protection against cardiovascular disease. However, the association between specific lipoprotein classes and first ischemic stroke (IS) has not been well defined, particularly in higher-risk hypertensive populations. Our study evaluated the associations of HDL-C with first IS in a Chinese hypertensive population.

Methods: The study population was obtained from a community-based cohort study of hypertension in Lianyungang and Rongcheng, China. A nested case-control design was used that included 2463 identified first IS cases and 2463 controls matched by age \pm 1 year, sex, and region.

Results: After adjusting for potential confounders, HDL-C was inversely associated with first IS (adjusted odds ratio [aOR]: 0.91; 95\% confidence interval [CI]: 0.85-0.98). HDL-C levels of at least $65.4 \mathrm{mg} / \mathrm{dL}$ displayed a significant protective effect for first IS (aOR: 0.82; 95\% CI: 0.69-0.98). Conversely, adverse effects of first IS were observed for low-density lipoprotein cholesterol (LDL-C) levels $\geq 138.1 \mathrm{mg} / \mathrm{dL}$ (aOR: 1.20; 95\% CI: 1.02-1.42) and triglyceride (TG) levels $\geq 140.8 \mathrm{mg} / \mathrm{dL}$ (aOR: 1.27 ; 95\% CI: 1.09-1.49). The risk associations of LDL-C and TG with first IS were attenuated in the presence of high HDL-C $(\geq 53.0 \mathrm{mg} / \mathrm{dL}$ ); an increased risk of first IS was only found in the presence of low HDL-C $(<53.0 \mathrm{mg} / \mathrm{dL})$ when LDL-C (aOR: 1.66; 95\% CI: 1.19-2.31) and TG (aOR: 1.47; 95\% CI: 1.17-1.84) were combined with HDL-C for analysis.

Conclusion: In this community-based Chinese hypertensive population, higher HDL-C was a significant protective factor of first IS. These data add to the evidence describing the relationship between lipids and IS and suggest that HDL-C maybe is a marker of IS risk in Chinses hypertensive population.

Keywords: high-density lipoprotein cholesterol, lipids, ischemic stroke, epidemiology

\section{Introduction}

China has one of the higher incidences of stroke in the world. The age-standardized prevalence, incidence, and mortality rates for stroke are 1114.8 per 100,000 people and 246.8 and 114.8 per 100,000 person-years, respectively. ${ }^{1}$ Many studies have provided strong evidence for dyslipidemia as a risk factor for coronary heart disease (CHD)., ${ }^{2,3}$ These studies demonstrate a positive relationship between low-density lipoprotein cholesterol (LDL-C) and $\mathrm{CHD}^{3}$ and an inverse relationship between high-density lipoprotein cholesterol (HDL-C) and CHD. ${ }^{2,4}$ However, these relationships have not been as clearly established for stroke, and some studies have even questioned whether cholesterol is a risk factor for stroke. ${ }^{5}$ 
In Asian populations, dyslipidemia is dominated by low HDL-C; conversely, dyslipidemia is dominated by high LDL-C in Western populations. ${ }^{6}$ In China, there is a higher prevalence of low HDL-C than of high LDL-C. ${ }^{7}$ Therefore, the relationship between HDL-C and the risk of stroke requires further analysis in China. Data from statin trials show impressive reductions in stroke risk among persons with cerebrovascular disease (CVD). ${ }^{8}$ However, some researchers have suggested that the improvement in cerebrovascular end points with statin agents cannot be completely explained by baseline values or treated LDL-C levels alone. ${ }^{9}$ Few studies have evaluated the combined association of HDL-C with LDL-C on first IS. ${ }^{10}$ Thus, it remains unclear whether people with high levels of both HDL-C and LDL-C have a lower risk of stroke than people with low levels of HDL-C and high levels of LDL-C.

Hypertension is the strongest risk factor for stroke. The incidence of hypertension among the Chinese population is very high. However, few studies have focus on the association between dyslipidemia and the risk of stroke in people with hypertension. The purpose of this study was to evaluate the individual and combined associations between specific lipid profiles and the incident risk of first IS in a Chinese hypertensive population without a history of prior stroke or CHD.

\section{Methods}

\section{Study Population}

The study population was obtained from the "H-type Hypertension Prevention and Control Public Service Project" (HHPCP), which is a community-based cohort study that was conducted in Lianyungang and Rongcheng, China, from 2016 to 2018. Eligible participants included individuals aged $\geq 35$ years with hypertension, which was defined as a seated resting systolic blood pressure (SBP) $>140 \mathrm{mmHg}$ or diastolic blood pressure (DBP) $>90 \mathrm{mmHg}$ at both the screening and recruitment visit, or as those who were taking antihypertensive medication. Physical examinations, questionnaire interviews, and biological samples were performed to collect the data. Baseline information on demographic, medical history, and lifestyle characteristics was collected via questionnaires and included data on age, sex, occupation, diet, sleep patterns, exercise, alcohol consumption, cigarette smoking, history of CHD, chronic kidney disease, diabetes mellitus, hypertension, hyperlipidemia and cancer, and medication use. Measurements of height, weight, body mass index (BMI), waistline, SBP, and DBP at the baseline examination were obtained using standardized protocols. The incidence of first stroke, which was the only outcome in this analysis, was defined as a first nonfatal or fatal stroke and included ischemic and hemorrhagic stroke. However, this analysis only evaluated ischemic stroke because few cases of hemorrhagic stroke were available. Stroke endpoint data were obtained from local Centers for Disease Control and Prevention (CDC) surveillance data collected between 2016 and 2018.

The Ethics Committee of the Institute of Biomedicine, Anhui Medical University, Hefei, China, the Ethics Committee of Lianyungang Precision Health Institute, and the Ethics Committee of the Lianyungang Center for Advanced Research in Cardiovascular Diseases approved this study. All participants provided written informed consent. The study was conducted in accordance with the Declaration of Helsinki.

\section{Nested Case-Control Study}

This nested case-control study was established from the HHPCP based on the following criteria: ${ }^{1}$ all registered patients were linked by their unique national ID with CDC surveillance data to identify the incidence of stroke between 2016 and $2018 ;^{2}$ the first stroke incidence in the CDC database occurred subsequent to obtaining the baseline data in the community survey. The controls were comprised of individuals selected from the study population who did not have a history of stroke and had complete data. The controls were matched with cases by age ( \pm 1 year), sex, and region in a 1:1 ratio. The total eligible population included 3546 incident stroke cases and 3546 matched controls. None of the cases or controls had a history of self-reported or doctor-diagnosed stroke or transient ischemic attack. Finally, 2463 ischemic cases and 2463 controls were included for analysis after excluding 466 hemorrhagic cases and matched controls, participants with CHD ( $\mathrm{n}=558)$, those who were using lipid-lowering drugs $(n=35)$ and antiplatelet drugs $(n=76)$, and unmatched cases $(n=565)$ (Online Figure I).

\section{Laboratory Assays}

Fasting serum HDL-C, triglyceride (TG), total cholesterol (TC), glucose, and total homocysteine concentrations were measured with their respective automatic clinical analyzers (Beckman Coulter) in a commercial lab (Shenzhen Tailored 
Medical laboratory, China). LDL-C concentrations were calculated according to the Friedewald formula. ${ }^{11}$

\section{Statistical Analysis}

The baseline characteristics are presented as means \pm SDs for continuous variables and as proportions for categorical variables. Chi-square tests for categorical variables and t-tests for continuous variables were used to compare differences in baseline characteristics between the cases and controls. Odds ratios (ORs) and 95\% confidence intervals (CIs) were estimated using a conditional logistic regression with and without adjustment for BMI, SBP, DBP, fasting glucose, total plasma homocysteine, smoking and consumption status, estimated glomerular filtration rate, antihypertensive drugs, and glucose-lowering drugs at baseline. When individual or combined lipids were analyzed, the other lipids were adjusted accordingly. Moreover, possible modifications of the associations between HDL-C or TG and first IS were assessed for variables including sex, age ( $<68$ vs $>68$ years), BMI ( $<24 \mathrm{vs}>24 \mathrm{~kg} / \mathrm{m}^{2}$ ), smoking status (never vs ever), alcohol consumption (never vs ever), SBP ( $<140$ vs $>140$ $\mathrm{mmHg}$ ), fasting glucose $(<5.6 \mathrm{vs}>5.6 \mathrm{mmol} / \mathrm{L})$, total plasma homocysteine concentration $(<15 \mathrm{vs}>15 \mathrm{umol} /$ L), TC $(<200$ vs $>200 \mathrm{mg} / \mathrm{dL})$, and LDL-C $(<130$ vs $>130 \mathrm{mg} / \mathrm{dL}$ ). Specifically, TG levels ( $<150 \mathrm{vs}>150 \mathrm{mg} /$ dL) were included when the association between HDL-C and first IS was explored, and HDL-C (males $<40$ /females $<50$ vs males $>40 /$ females $>50 \mathrm{mg} / \mathrm{dL}$ ) was included when the TG-first IS association was explored.

A two-tailed $\mathrm{P}<0.05$ was considered statistically significant in all analyses. R software (version 3.3.1; http:// www.R-project.org) was used for all statistical analyses.

\section{Data Availability}

The study protocol and statistical analysis plan of this article are available from the corresponding author upon reasonable request. All data requests should first be submitted to Gang Li for consideration. Access to available fully anonymized data may be granted 12 months after publication. Requesters will be asked to complete an application form detailing specific requirements, rationale, and proposed use. A data-sharing agreement must be signed. Requested data will be made available, along with supporting documentation (eg, data dictionary) on a secure server.

\section{Results}

\section{Study Participants and Baseline Characteristics}

We analyzed 2463 IS cases and 2463 matched controls (Table 1). The cases were more likely to have higher SBP $(153.1 \pm 21.9$ vs $147.7 \pm 20.8 \mathrm{mmHg}, \mathrm{P}<0.001)$, DBP $(90.0 \pm 13.7$ vs $86.7 \pm 13.1 \mathrm{mmHg}, \mathrm{P}<0.001)$, fasting glucose levels $(6.5 \pm 2.5$ vs $6.0 \pm 2.0 \mathrm{mmol} / \mathrm{L}, \mathrm{P}<0.001)$, BMI $\left(26.0 \pm 4.0\right.$ vs $\left.25.5 \pm 3.7 \mathrm{~kg} / \mathrm{m}^{2}, \mathrm{P}<0.001\right)$, and total homocysteine levels $(14.1 \pm 7.8$ vs $13.5 \pm 8.8 \mathrm{umol} / \mathrm{L}, \mathrm{P}=$ 0.009) than controls. Because of our matching criteria, cases and controls were similar in age and sex. In the analysis of baseline lipid profiles, compared to the controls, IS cases had significantly higher levels of TG (143.7 \pm 96.0 vs $129.0 \pm 86.2 \mathrm{mg} / \mathrm{dL}, \mathrm{P}<0.001)$ and LDL-C $(128.7 \pm 32.7$ vs $126.1 \pm 32.4, \quad \mathrm{P}=0.004)$ but a significantly lower level of HDL-C $(59.6 \pm 15.1$ vs $62.0 \pm 15.6 \mathrm{mg} / \mathrm{dL}, \mathrm{P}<0.001)$; the mean $\mathrm{TC}$ level was similar in the two groups $(213.2 \pm 47.4$ vs $212.8 \pm$ $46.5 \mathrm{mg} / \mathrm{dL}, \mathrm{P}=0.751)($ Table 1$)$.

\section{Associations of Specific Types of Blood Lipids with First IS}

When HDL-C levels were examined as a continuous variable in an adjusted model that included potential confounders and TG and LDL-C levels, a protective effect was found with an adjusted odds ratio (aOR) of 0.91 (95\% CI: $0.85-0.98$ ) for one SD increase in the HDL-C level. This translated into a $9 \%$ reduction in the odds of experiencing stroke (Figure 1A). When HDL-C levels were categorized as tertiles, a significant protective effect was observed for IS in patients with levels of at least $65.4 \mathrm{mg} / \mathrm{dL}$ (aOR: 0.82; 95\% CI: 0.69-0.98; P for trend $=0.029$ ). However, this significant association was no longer present when HDL-C was categorized according to the current clinical criteria $(<40 \mathrm{mg} / \mathrm{dL}$ in males and $<50 \mathrm{mg} / \mathrm{dL}$ in females) (Table 2). Furthermore, none of the baseline variables showed effect modification of the associations between HDL-C and IS after the stratified analyses (Online Table I).

There was a significant positive association between TG levels and the risk of first IS after adjustment for potential confounders, as shown in Figure 1B. A one SD increase in TG concentration was associated with a $10 \%$ increased risk of first IS (aOR: 1.10 ; 95\% CI: 1.02-1.17). When TG and LDL-C levels were categorized as tertiles, a significant adverse effect of first IS was observed for TG 
Table I Baseline Characteristics of Study Participants with First Ischemic Stroke and Age- and Sex-Matched Controls

\begin{tabular}{|c|c|c|c|}
\hline & Control Subjects $(n=2463)$ & First Ischemic Stroke $(n=2463)$ & $P$ value \\
\hline Age, yrs & $67.6 \pm 9.4$ & $67.6 \pm 9.4$ & 0.998 \\
\hline Male, no. (\%) & $1110(45.1)$ & $1110(45.1)$ & 1.000 \\
\hline $\mathrm{SBP}, \mathrm{mmHg}$ & $147.7 \pm 20.8$ & $153.1 \pm 21.9$ & $<0.001$ \\
\hline $\mathrm{DBP}, \mathrm{mmHg}$ & $86.7 \pm 13.1$ & $90.0 \pm 13.7$ & $<0.001$ \\
\hline $\mathrm{BMI}, \mathrm{kg} / \mathrm{m}^{2}$ & $25.5 \pm 3.7$ & $26.0 \pm 4.0$ & $<0.001$ \\
\hline Fasting glucose, $\mathrm{mg} / \mathrm{dL}$ & $6.0 \pm 2.0$ & $6.5 \pm 2.5$ & $<0.001$ \\
\hline History of diabetes, yes, no. (\%) & $222(9.0)$ & $363(14.7)$ & $<0.001$ \\
\hline $\mathrm{TC}, \mathrm{mg} / \mathrm{dL}$ & $212.8 \pm 46.5$ & $213.2 \pm 47.4$ & 0.751 \\
\hline $\mathrm{TG}, \mathrm{mg} / \mathrm{dL}$ & $129.0 \pm 86.2$ & $143.7 \pm 96.0$ & $<0.001$ \\
\hline $\mathrm{HDL}-\mathrm{C}, \mathrm{mg} / \mathrm{dL}$ & $62.0 \pm 15.6$ & $59.6 \pm 15.1$ & $<0.001$ \\
\hline LDL-C, mg/dL & $126.1 \pm 32.4$ & $128.7 \pm 32.7$ & 0.004 \\
\hline Total homocysteine, $\mu \mathrm{mol} / \mathrm{L}$ & $13.5 \pm 8.8$ & $14.1 \pm 7.8$ & 0.009 \\
\hline$\geq 15 \mu \mathrm{mol} / \mathrm{L}$, no. (\%) & $558(22.7)$ & $675(27.4)$ & $<0.001$ \\
\hline Smoking status, no. (\%) & & & 0.051 \\
\hline Never & $1786(72.5)$ & $1754(7 \mid .2)$ & \\
\hline Former & $196(8.0)$ & $168(6.8)$ & \\
\hline Current & $48 \mid(19.5)$ & $54 I(22.0)$ & \\
\hline Alcohol consumption, no. (\%) & & & 0.001 \\
\hline Never & $1785(72.5)$ & $1849(75.1)$ & \\
\hline Former & $89(3.6)$ & $120(4.9)$ & \\
\hline Current & $589(23.9)$ & $492(20.0)$ & \\
\hline Antihypertensive drugs, yes, no. (\%) & $906(36.8)$ & $1193(48.4)$ & $<0.001$ \\
\hline Glucose lowering drugs, yes, no. (\%) & $105(4.3)$ & $198(8.0)$ & $<0.001$ \\
\hline eGFR, $\mathrm{mL} / \mathrm{min}$ per $1.73 \mathrm{~m}^{2}$ & $95.0 \pm 13.8$ & $93.9 \pm 14.6$ & 0.007 \\
\hline
\end{tabular}

levels of at least $140.8 \mathrm{mg} / \mathrm{dL}$ (aOR: 1.27 ; 95\% CI: $1.09-$ 1.49; $\mathrm{P}$ for trend $=0.003$ ) and LDL-C levels of at least $138.1 \mathrm{mg} / \mathrm{dL}$ (aOR: $1.20 ; 95 \%$ CI: $1.02-1.42 ; \mathrm{P}$ for trend $=$ 0.027) (Table 2). When LDL-C levels were examined as a continuous variable, no significant positive association was found with an aOR of 1.04 (95\% CI: 0.97-1.12) for one SD increase in the LDL-C level (Figure 1C) (Table 2). There was no significant relationship between TC levels and the risk of IS (Figure 1D) (Table 2).

\section{Combined Associations of HDL-C and LDL-C or TG with First IS}

We performed stratified analyses to assess the effect of LDL-C (per one SD increment) on first IS by HDL-C tertiles. Figure 2A, which displays the association between
LDL-C and the risk of first IS, indicates that there were different tendencies with different HDL-C levels. Only low HDL-C levels $(<53.0 \mathrm{mg} / \mathrm{dL})$ displayed a positive tendency with IS. The positive relationship between LDL-C and the risk of IS was attenuated in patients with higher HDL-C levels $(\geq 53.0 \mathrm{mg} / \mathrm{dL})$. Similarly, when LDL-C levels were categorized as tertiles, the highest risk for first IS was reported in participants with low HDL-C $(<53.0 \mathrm{mg} / \mathrm{dL})$ and high LDL-C $(>138.1 \mathrm{mg} / \mathrm{dL})$ levels; these participants had a $66 \%$ higher risk of first IS than those with high HDL-C $(>65.4 \mathrm{mg} / \mathrm{dL})$ and low LDLC (<111.4 mg/dL) levels (aOR: 1.66; 95\% CI: 1.19-2.31; $\mathrm{P}=0.003$ ) (Table 3 ). The other combinations of HDL-C and LDL-C showed no significant associations with first IS. 
A

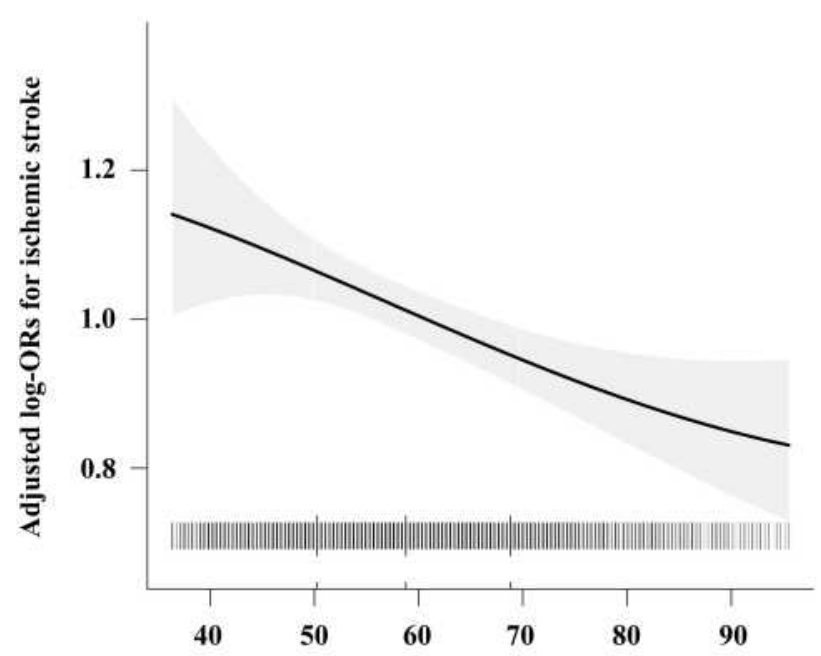

HDL-C, mg/dL

\section{C}

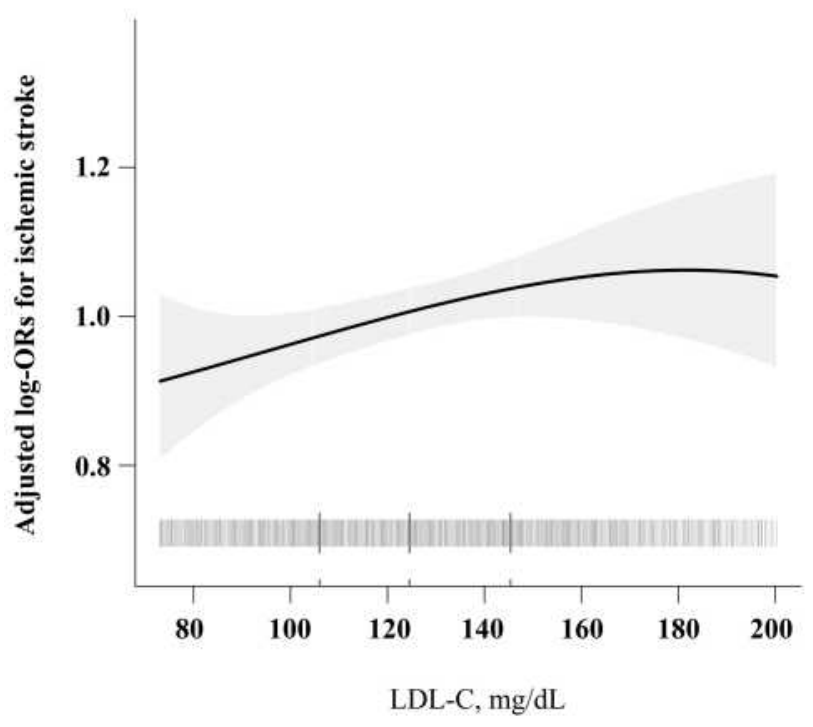

B

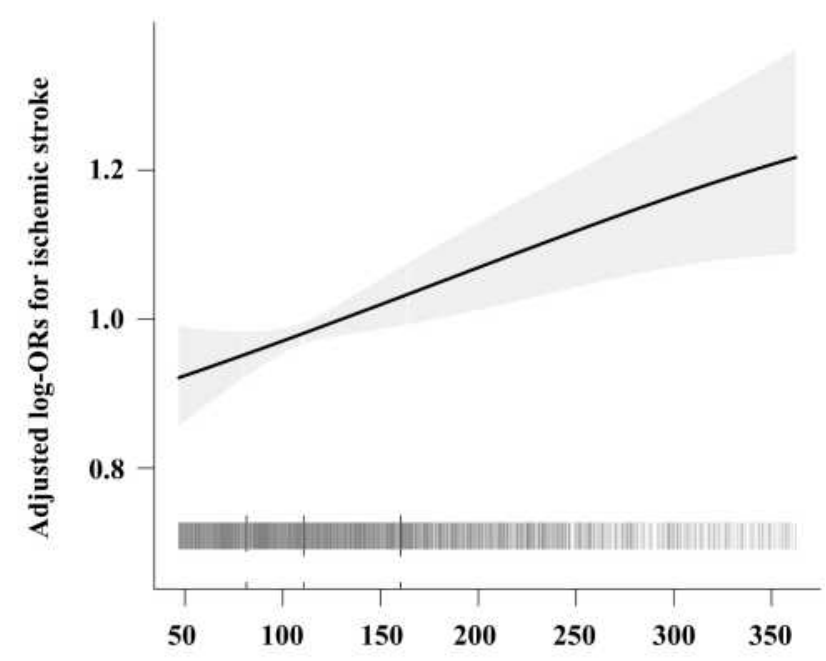

$\mathrm{TG}, \mathrm{mg} / \mathrm{dL}$

D

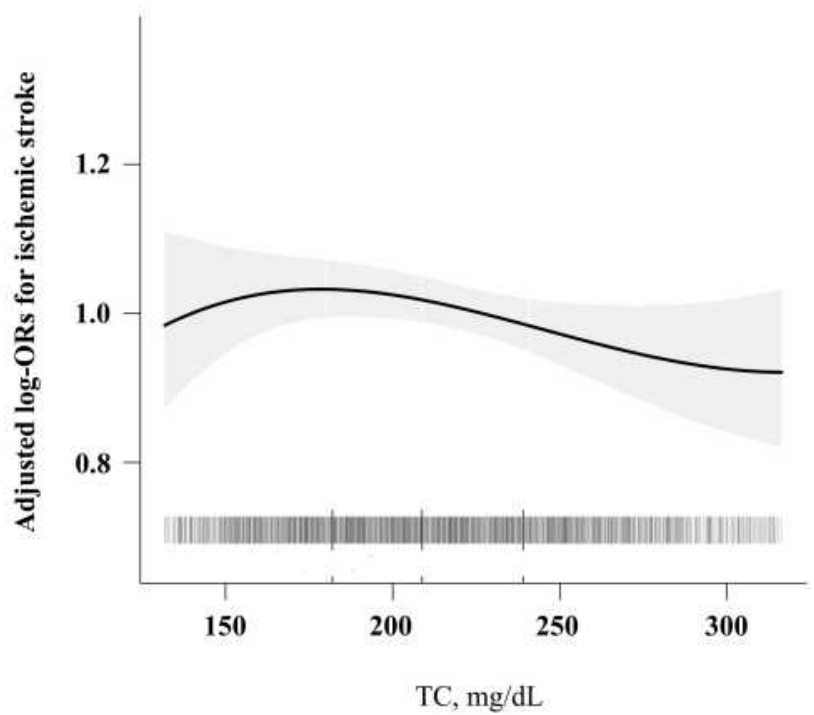

Figure I Smoothing curves for the association of first IS with HDL-C, TG, LDL-C and TC. All the panels adjusted for body mass index (BMI), systolic blood pressure (SBP), diastolic blood pressure (DBP), fasting glucose, smoking status, alcohol consumption, use of antihypertensive drugs, and glucose-lowering drugs, total homocysteine (tHcy), and estimated glomerular filtration rate (eGFR). HDL-C (A): adjusted for all the above variables plus TG and LDL-C.TG (B): adjusted for all the above variables plus TC. LDL-C (C): adjusted for all the above variables plus HDL-C and TG.TC (D): adjusted for all the above variables plus TG.

In the combined analysis investigating the associations of HDL-C and TG levels with first IS, the association of TG with first IS displayed a positive tendency only at lower HDL-C levels $(<65.4 \mathrm{mg} / \mathrm{dL})$; conversely, no significant association was found between the highest HDL-C tertile $(>65.4 \mathrm{mg} / \mathrm{dL})$ (Figure $2 \mathrm{~B})$. Similarly, patients with low HDL-C $(<53.0 \mathrm{mg} / \mathrm{dL})$ and high TG $(>140.8 \mathrm{mg} / \mathrm{dL})$ levels had a $47 \%$ higher risk of first IS (aOR: 1.147; 95\%
CI: $1.17-1.84 ; \mathrm{P}<0.001)$ than those with high HDL-C $(>65.4 \mathrm{mg} / \mathrm{dL})$ and low $\mathrm{TG}(<89.5 \mathrm{mg} / \mathrm{dL})$ levels (Table 4).

\section{Discussion}

To our knowledge, this is the first study to evaluate the prospective association between lipid profiles and the risk of IS in a community-based Chinese hypertensive 
Table 2 Association of Fasting Serum Lipid Levels with Incident Risk of First Ischemic Stroke

\begin{tabular}{|c|c|c|c|c|c|c|}
\hline & $\mathbf{N}$ & Cases (\%) & Crude Model OR (95\% Cl) & $P$ value & Adjusted Model* OR (95\% Cl) & $P$ value \\
\hline HDL-C ${ }^{\#}, \mathbf{m g} / \mathbf{d L}$ & & & & & & \\
\hline Continuous, Per SD & 4926 & $2463(50.0)$ & $0.84(0.79,0.89)$ & $<0.001$ & $0.91(0.85,0.98)$ & 0.014 \\
\hline $\begin{array}{l}\text { Tertiles } \\
\text { TI }(<53.0) \\
\text { T2 }(53.0-65.4) \\
\text { T3 }(\geq 65.4) \\
\text { P for trend }\end{array}$ & $\begin{array}{l}1600 \\
1685 \\
1641\end{array}$ & $\begin{array}{l}873(54.6) \\
846(50.2) \\
744(45.3)\end{array}$ & $\begin{array}{l}\text { Ref } \\
0.83(0.72,0.95) \\
0.67(0.58,0.77)\end{array}$ & $\begin{array}{l}0.007 \\
<0.001 \\
<0.001\end{array}$ & $\begin{array}{l}\text { Ref } \\
0.92(0.79,1.08) \\
0.82(0.69,0.98)\end{array}$ & $\begin{array}{l}0.328 \\
0.030 \\
0.029\end{array}$ \\
\hline $\begin{array}{l}\text { Clinical cut-off } \\
\text { Males }<40 / \text { Females }<50 \\
\text { Males } \geq 40 / \text { Females } \geq 50\end{array}$ & $\begin{array}{l}763 \\
4163\end{array}$ & $\begin{array}{l}417(54.7) \\
2046(49.1)\end{array}$ & $\begin{array}{l}\text { Ref } \\
0.79(0.67,0.92)\end{array}$ & 0.004 & $\begin{array}{l}\text { Ref } \\
0.93(0.77,1.13)\end{array}$ & 0.454 \\
\hline $\mathbf{T G}^{\dagger}, \mathbf{m g} / \mathbf{d L}$ & & & & & & \\
\hline Continuous, Per SD & 4926 & $2463(50.0)$ & $1.20(1.13,1.28)$ & $<0.001$ & $1.10(1.02,1.17)$ & 0.007 \\
\hline $\begin{array}{l}\text { Tertiles } \\
\text { TI }(<89.5) \\
\text { T2 }(89.5-\mid 40.8) \\
\text { T3 }(\geq \mid 40.8) \\
\text { P for trend }\end{array}$ & $\begin{array}{l}1628 \\
1647 \\
1651\end{array}$ & $\begin{array}{l}738(45.3) \\
810(49.2) \\
915(55.4)\end{array}$ & $\begin{array}{l}\text { Ref } \\
\text { I.I8 }(1.03,1.36) \\
1.55(1.34,1.79)\end{array}$ & $\begin{array}{l}0.017 \\
<0.001 \\
<0.001\end{array}$ & $\begin{array}{l}\text { Ref } \\
1.06(0.92,1.23) \\
1.27(1.09,1.49)\end{array}$ & $\begin{array}{l}0.405 \\
0.003 \\
0.003\end{array}$ \\
\hline $\begin{array}{l}\text { Clinical cut-off } \\
\quad<150 \\
\geq 150\end{array}$ & $\begin{array}{l}3480 \\
1446\end{array}$ & $\begin{array}{l}1666(47.9) \\
797(55.1)\end{array}$ & $\begin{array}{l}\text { Ref } \\
1.36(1.19,1.54)\end{array}$ & $<0.001$ & $\begin{array}{l}\text { Ref } \\
1.17(1.02,1.34)\end{array}$ & 0.025 \\
\hline LDL-C\|, mg/dL & & & & & & \\
\hline Continuous, Per SD & 4926 & $2463(50.0)$ & $1.10(1.04,1.17)$ & 0.002 & $1.04(0.97,1.12)$ & 0.239 \\
\hline $\begin{array}{l}\text { Tertiles } \\
\text { T1 }(<|1| .4) \\
\text { T2 }(1 \mid 1.4-138.1) \\
\text { T3 }(\geq \mid 38.1) \\
\text { P for trend }\end{array}$ & $\begin{array}{l}1647 \\
1653 \\
1626\end{array}$ & $\begin{array}{l}769(46.7) \\
827(50.0) \\
867(53.3)\end{array}$ & $\begin{array}{l}\text { Ref } \\
1.17(1.02,1.35) \\
1.36(1.17,1.57)\end{array}$ & $\begin{array}{l}0.027 \\
<0.001 \\
<0.001\end{array}$ & $\begin{array}{l}\text { Ref } \\
1.10(0.95,1.28) \\
1.20(1.02,1.42)\end{array}$ & $\begin{array}{l}0.203 \\
0.027 \\
0.027\end{array}$ \\
\hline $\begin{array}{l}\text { Clinical cut-off } \\
\quad<130 \\
\geq 130\end{array}$ & $\begin{array}{l}2825 \\
2101\end{array}$ & $\begin{array}{l}1365(48.3) \\
1098(52.3)\end{array}$ & $\begin{array}{l}\text { Ref } \\
1.20(1.06,1.35)\end{array}$ & 0.004 & $\begin{array}{l}\text { Ref } \\
\text { I.II (0.97,I.27) }\end{array}$ & 0.116 \\
\hline $\mathrm{TC}^{\ddagger}, \mathrm{mg} / \mathrm{dL}$ & & & & & & \\
\hline Continuous, Per SD & 4926 & $2463(50.0)$ & I.0I $(0.95,1.08)$ & 0.723 & $0.98(0.91,1.05)$ & 0.512 \\
\hline $\begin{array}{l}\text { Tertiles } \\
\qquad \text { TI }(<190.6) \\
\text { T2 }(190.6-229.3) \\
\text { T3 }(\geq 229.3) \\
\text { P for trend }\end{array}$ & $\begin{array}{l}1648 \\
1637 \\
164 \mid\end{array}$ & $\begin{array}{l}817(49.6) \\
824(50.3) \\
822(50.1)\end{array}$ & $\begin{array}{l}\text { Ref } \\
1.03(0.90,1.19) \\
1.03(0.88,1.19)\end{array}$ & $\begin{array}{l}0.648 \\
0.742 \\
0.743\end{array}$ & $\begin{array}{l}\text { Ref } \\
1.06(0.91,1.23) \\
0.96(0.81,1.13)\end{array}$ & $\begin{array}{l}0.441 \\
0.606 \\
0.603\end{array}$ \\
\hline $\begin{array}{l}\text { Clinical cut-off } \\
\quad<200 \\
\geq 200\end{array}$ & $\begin{array}{l}2077 \\
2849\end{array}$ & $\begin{array}{l}1034(49.8) \\
1429(50.2)\end{array}$ & $\begin{array}{l}\text { Ref } \\
1.02(0.90,1.15)\end{array}$ & 0.781 & $\begin{array}{l}\text { Ref } \\
0.98(0.86,1.12)\end{array}$ & 0.769 \\
\hline
\end{tabular}

Notes: Adjusted model*: adjusted for body mass index (BMI), systolic blood pressure (SBP), diastolic blood pressure (DBP), fasting glucose, smoking status, alcohol consumption, use of antihypertensive drugs, and glucose-lowering drugs, total homocysteine (tHcy), and estimated glomerular filtration rate (eGFR). ${ }^{\#}$ For HDL, adjusted for all the above variables plus TG and LDL-C. ' For TG, adjusted for all the above variables plus TC. ${ }^{\dagger}$ For TC, adjusted for all the above variables plus TG. "For LDL, adjusted for all the above variables plus HDL-C and TG. 

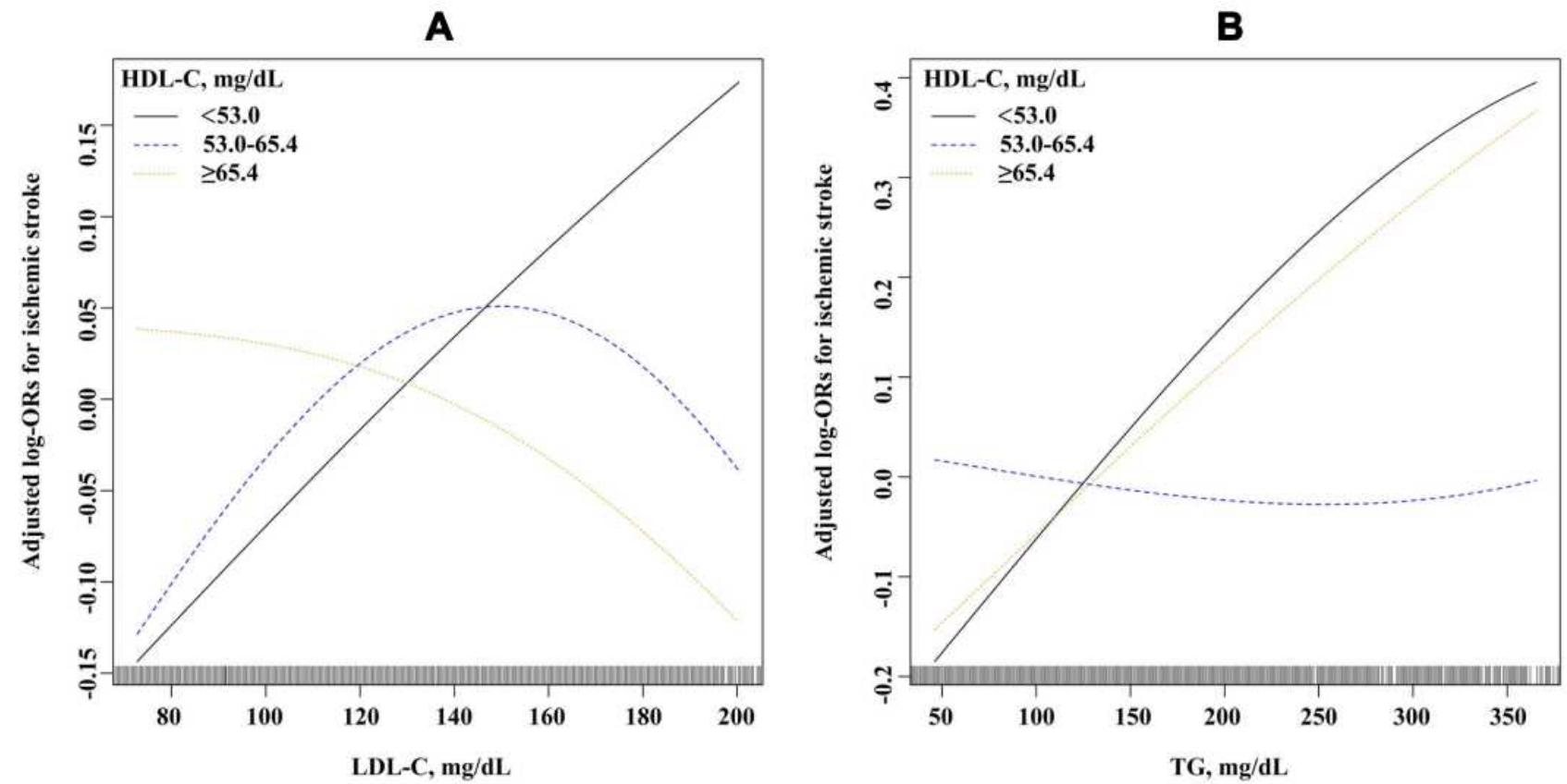

Figure 2 Association of LDL-C or TG with first IS stratified by HDL-C levels. (A) Adjusted for body mass index (BMI), systolic blood pressure (SBP), diastolic blood pressure (DBP), fasting glucose, smoking status, alcohol consumption, use of antihypertensive drugs, and glucose-lowering drugs, total homocysteine (tHcy), and estimated glomerular filtration rate (eGFR) and TG (continuous). (B) Adjusted for body mass index (BMI), systolic blood pressure (SBP), diastolic blood pressure (DBP), fasting glucose, smoking status, alcohol consumption, use of antihypertensive drugs, and glucose-lowering drugs, total homocysteine (thcy), and estimated glomerular filtration rate (eGFR) and LDL-C (continuous).

population with no history of stroke and CHD. Our study contributes the following new insights into the HDL-C-IS association, for which previous studies have yielded conflicting results. This community-based case-control study demonstrated a protective effect of higher HDL-C levels for IS in a Chinese hypertensive population. This protective relationship was also observed in the combined analysis of HDL-C levels with LDL-C or TG and the risk of IS. In this combined analysis, elevated LDL-C and TG levels were no longer positively associated with first IS in the presence of higher HDL-C levels.

The relationship between abnormal serum lipid levels and stroke is less clear than this relationship for CHD. The protective effects of increased HDL-C levels on the risk of myocardial infarction have been established by numerous epidemiological studies; ${ }^{6}$ however, this protective effect was not clear for stroke. Some cohort studies including the Framingham Heart Study have reported no association

Table 3 Combined Association of HDL-C and LDL-C Tertiles with First IS

\begin{tabular}{|c|c|c|c|c|c|}
\hline HDL-C Tertiles mg/dL & LDL-C Tertiles mg/dL & $\mathbf{N}(\%)$ & Crude OR $(95 \% \mathrm{Cl})$ & Adjusted OR* (95\% Cl) & P-value \\
\hline \multirow[t]{3}{*}{ TI $(\geq 65.4)$} & $<111.4$ & $180(40.8)$ & Ref & Ref & \\
\hline & $111.4-138.1$ & $236(45.8)$ & $1.22(0.94,1.58)$ & I. $10(0.84,1.45)$ & 0.483 \\
\hline & $\geq|38|$. & $328(47.9)$ & $1.32(1.03,1.69)$ & I. $10(0.85,1.43)$ & 0.479 \\
\hline \multirow[t]{3}{*}{ T2 (53.0-65.4) } & $<1|| .4$ & $228(46.5)$ & $1.26(0.97,1.64)$ & I. $12(0.85, \mathrm{I} .47)$ & 0.425 \\
\hline & $111.4-138.1$ & $302(49.7)$ & $1.45(1.13,1.86)$ & I.2। $(0.92,1.57)$ & 0.169 \\
\hline & $\geq 138.1$ & $316(53.8)$ & $1.69(1.31,2.17)$ & I.27 $(0.97,1.67)$ & 0.088 \\
\hline \multirow[t]{3}{*}{ T3 $(<53.0)$} & $<111.4$ & $361(50.4)$ & $1.45(1.14,1.85)$ & I.I6 $(0.89, \mid .5 \mathrm{I})$ & 0.278 \\
\hline & $111.4-138.1$ & $289(54.5)$ & $1.75(1.35,2.27)$ & I.25 $(0.94,1.67)$ & 0.123 \\
\hline & $\geq 138.1$ & $223(63.0)$ & $2.47(1.85,3.30)$ & $1.66(1.19,2.31)$ & 0.003 \\
\hline
\end{tabular}

Notes: *Adjusted for body mass index (BMI), systolic blood pressure (SBP), diastolic blood pressure (DBP), fasting glucose, smoking status, alcohol consumption, use of antihypertensive drugs, and glucose-lowering drugs, total homocysteine (tHcy), and estimated glomerular filtration rate (eGFR), and TG (continuous). 
Table 4 Combined Association of HDL-C and TG Tertiles with First IS

\begin{tabular}{|c|c|c|c|c|c|}
\hline HDL-C Tertiles mg/dL & TG Tertiles mg/dL & $\mathbf{N}(\%)$ & Crude OR $(95 \% \mathrm{Cl})$ & Adjusted $\mathrm{OR}^{\#}(95 \% \mathrm{Cl})$ & P-value \\
\hline \multirow[t]{3}{*}{ TI $(\geq 65.4)$} & $<89.5$ & $346(42.5)$ & Ref & Ref & \\
\hline & $89.5-140.8$ & $266(46.1)$ & I.I6 $(0.93,1.44)$ & $1.00(0.79,1.26)$ & 0.992 \\
\hline & $\geq 140.8$ & $132(53.0)$ & $1.53(1.14,2.04)$ & $1.23(0.89,1.69)$ & 0.205 \\
\hline \multirow[t]{3}{*}{ T2 (53.0-65.4) } & $<89.5$ & $255(47.0)$ & I.22 $(0.98, \mid .5 I)$ & I. $10(0.87,1.40)$ & 0.410 \\
\hline & $89.5-140.8$ & $314(51.0)$ & $1.43(1.16,1.77)$ & $1.23(0.98,1.53)$ & 0.074 \\
\hline & $\geq 140.8$ & $277(52.6)$ & $1.53(1.23,1.92)$ & $1.21(0.95,1.54)$ & 0.122 \\
\hline \multirow[t]{3}{*}{ T3 $(<53.0)$} & $<89.5$ & $137(50.6)$ & $1.38(1.05,1.83)$ & I.I8 $(0.86,1.60)$ & 0.302 \\
\hline & $89.5-140.8$ & $230(50.7)$ & $1.39(1.10,1.75)$ & I.I3 $(0.87,1.46)$ & 0.356 \\
\hline & $\geq 140.8$ & $506(57.8)$ & $1.94(1.59,2.37)$ & I.47 (I.I7,I.84) & $<0.001$ \\
\hline
\end{tabular}

Notes: ${ }^{\#}$ Adjusted for body mass index (BMI), systolic blood pressure (SBP), diastolic blood pressure (DBP), fasting glucose, smoking status, alcohol consumption, use of antihypertensive drugs, and glucose-lowering drugs, total homocysteine (tHcy), and estimated glomerular filtration rate (eGFR), and LDL-C (continuous).

between HDL-C and IS; ${ }^{12}$ however, some epidemiological studies support an inverse association. ${ }^{13-15}$ The absence of a consistent relationship between HDL-C and stroke may be partially explained by the heterogeneity of stroke, the focus on cardiovascular events rather than on stroke events, and the lack of classification of stroke subtypes. Furthermore, no significant reduction in CVD was observed including IS events in the AIM-HIGH and HPS2-THRIVE studies in association with HDL-C levels. ${ }^{16,17}$ However, these studies evaluated patients with a history of CVD. In contrast to the many studies conducted in Western countries, few Asian studies have been performed in this field; moreover, HDL$\mathrm{C}$ levels were reported to be inversely associated with the risk of first IS in these studies. ${ }^{10,18,19}$ Our current study provides further evidence of a protective effect of HDL-C on first IS. Moreover, this protective association was not evident when using the current clinical binary threshold, which underscores the need to consider HDL-C as a continuous trait rather than the current binary cutoff. The mechanisms of how HDL-C protects against CVD including IS are often explained by the ability of HDL to remove cholesterol from the periphery for delivery to the liver and excretion in the bile, a process termed reverse cholesterol transport. ${ }^{20}$ The reverse cholesterol transport capacity of HDL-C is a potent protection for LDL-C oxidation ${ }^{21,22}$ and possesses antiinflammatory properties. ${ }^{23}$ Few previous studies have examined the combined associations of LDL-C and HDL-C with first IS. In a nested case-control study in the China Kadoorie Biobank (CKB) of Chinese populations, the associations of LDL-C and HDL-C with IS occurred independently of one another. ${ }^{10}$ However, we found that the association between LDL-C and first IS differed by HDL-C levels. A positive relationship was found between LDL-C and the risk of IS only when combined with a low HDL-C level $(<53.0 \mathrm{mg} /$ dL). In other words, high HDL-C might attenuate the association between LDL-C and IS. Notably, our participants and those from the CKB study display differing characteristics. First, the average age of IS cases in our study was 67.6 years whereas it was 54.3 years in the CKB study. Secondly, our study included participants with hypertension (mean SBP of $153.1 \mathrm{mmHg}$ for IS cases), whereas only slightly more than half of the participants were hypertensive (56.8\%) (mean SBP was $144.1 \mathrm{mmHg}$ for IS cases) in the CKB study.

The role of TG levels in atherosclerosis has remained unclear, and clinical recommendations have fluctuated from a need to reduce levels to not providing any advice on treatment. ${ }^{24}$ Some studies, but not all, support a positive association between TG and the risk of first IS. ${ }^{25,26}$ Our study found that higher TG levels were a significant risk factor for the first IS incident in this Chinese hypertensive population. Furthermore, our study showed that the TG-IS association varied according to HDL-C levels. Only patients with low HDL $(<53.0 \mathrm{mg} / \mathrm{dL})$ and high TG $(>140.8 \mathrm{mg} / \mathrm{dL})$ levels had a significantly increased risk of first IS. The combined association of high TG and low HDL-C levels strongly predicted CHD in many studies. ${ }^{27,28}$ Consistently, many studies have shown that adjusting for HDL-C attenuates the association of TG with the risk of CVD. ${ }^{29}$ The attenuation of the TG effect on CVD risk by high HDL-C is most likely caused by metabolic interactions. ${ }^{30}$

Several limitations of our study design deserve discussion. The fact that this study was conducted in a communitybased hypertensive population is both a strength and a limitation. The most important risk factor of atherosclerosis 
at the population level is hypertension, ${ }^{31}$ and a study found that the protective association between high HDL-C and stroke was more significant in the hypertension subgroup. ${ }^{32}$ However, our findings must be interpreted cautiously in nonhypertensive populations. Our study population was drawn from two coastal areas of China and thus may not represent the entire Chinese population. We only examined fasting lipids status and statin use at baseline, and it is not entirely clear whether the participants made changes to their diet or medications during the follow-up period. Although we controlled for important covariables, we cannot exclude the possibility of residual confounding. Finally, as an observational study, we cannot make a causal conclusion between lipid levels and first IS.

\section{Conclusions}

In this Chinese hypertensive population, we have shown that HDL-C levels were a significant protective factor for IS risk. Elevated LDL-C and TG levels were no longer associated with first IS in the presence of high HDL-C. These findings, if further confirmed, suggest a new paradigm that possibly shifts from LDL-C as the center of focus to HDL-C as an important player in first IS in Chinese hypertensive populations.

\section{Abbreviations}

aOR, adjusted odds ratio; BMI, body mass index; CDC, Centers for Disease Control and Prevention; CHD, coronary heart disease; CI, confidence interval; CVD, cardiovascular disease; DBP, diastolic blood pressure; HDL-C, high-density lipoprotein cholesterol; HHPCP, H-type Hypertension Prevention and Control Public Service Project; IS, ischemic stroke; LDL-C, low-density lipoprotein cholesterol; SBP, systolic blood pressure; TC, total cholesterol; TG, triglycerides.

\section{Acknowledgments}

We acknowledge the contribution of all the research staff as well as the study participants who have participated in this study. No medical writer or editor was involved in the creation of this manuscript. The abstract of this paper was presented at the International Stroke Conference 2020 name "HDL-C levels inversely associated with first ischemic stroke in a Chinese hypertensive population" as a poster presentation with interim findings. The poster's abstract was published in "Poster Abstracts" in Stroke Journal name "HDL-C levels inversely associated with first ischemic stroke in a Chinese hypertensive population”.

\section{Funding}

This study was supported by National Nature and Science Foundation of China (81601010, 81960074) and other governmental foundations (2018ZX09301034003; PWZxq2017-08; shslczdzk06103; PWYgf2018-05).

\section{Disclosure}

The authors report no conflicts of interest in this work.

\section{References}

1. Wang W, Jiang B, Sun H, et al. Prevalence, incidence, and mortality of stroke in China. Circulation. 2017;135(8):759-771. doi:10.1161/ CIRCULATIONAHA.116.025250

2. Barter P, Gotto AM, LaRosa JC, et al. HDL cholesterol, very low levels of LDL cholesterol, and cardiovascular events. $N$ Engl J Med. 2007;357(13):1301-1310. doi:10.1056/NEJMoa064278

3. Sharrett AR, Ballantyne CM, Coady SA, et al. Coronary heart disease prediction from lipoprotein cholesterol levels, triglycerides, lipoprotein(a), apolipoproteins A-I and B, and HDL density subfractions: the Atherosclerosis Risk in Communities (ARIC) Study. Circulation. 2001;104(10):1108-1113. doi:10.1161/hc3501.095214

4. Woodward M, Barzi F, Feigin V, et al. Associations between high-density lipoprotein cholesterol and both stroke and coronary heart disease in the Asia Pacific region. Eur Heart J. 2007;28 (21):2653-2660. doi:10.1093/eurheartj/ehm427

5. Willey J, Gonzalez-Castellon M. Cholesterol level and stroke: a complex relationship. JAMA Intern Med. 2013;173 (19):1765-1766. doi:10.1001/jamainternmed.2013.10100

6. Huxley RR, Barzi F, Lam TH, et al. Isolated low levels of high-density lipoprotein cholesterol are associated with an increased risk of coronary heart disease: an individual participant data meta-analysis of 23 studies in the Asia-Pacific region. Circulation. 2011;124(19):2056-2064. doi:10.1161/CIRCULATIONAHA.111.028373

7. Yang W, Xiao J, Yang Z, et al. Serum lipids and lipoproteins in Chinese men and women. Circulation. 2012;125(18):2212-2221. doi:10.1161/CIRCULATIONAHA.111.065904

8. SPARCL Investigators. High-dose atorvastatin after stroke or transient ischemic attack. $N$ Engl $J$ Med. 2006;355(6):549-559. doi:10.1056/NEJMoa061894

9. Pedersen TR, Kjekshus J, Berg Ket al., Baseline serum cholesterol and treatment effect in the Scandinavian Simvastatin Survival Study (4S). Lancet (London). 1995;345(8960):1274-1275. doi:10.1016/ S0140-6736(95)90926-5

10. Sun L, Clarke R, Bennett D, et al. Causal associations of blood lipids with risk of ischemic stroke and intracerebral hemorrhage in Chinese adults. Nat Med. 2019;25(4):569-574. doi:10.1038/s41591-019-0366-x

11. Choukem SP, Manases T, Nda-Mefoo JP, et al. Validation of the Friedewald formula for the estimation of low density lipoprotein cholesterol in a sub-Saharan African population. Clin Biochem. 2018;53:25-30. doi:10.1016/j.clinbiochem.2017.12.008

12. Wolf PA, D'Agostino RB, Belanger AJ, Kannel WB. Probability of stroke: a risk profile from the Framingham Study. Stroke. 1991;22 (3):312-318. doi:10.1161/01.STR.22.3.312

13. Shahar E, Chambless LE, Rosamond WD, et al. Plasma lipid profile and incident ischemic stroke: the Atherosclerosis Risk in Communities (ARIC) study. Stroke. 2003;34(3):623-631. doi:10.1161/01.STR.0000057812.51734.FF

14. Willey JZ, Xu Q, Boden-Albala B, et al. Lipid profile components and risk of ischemic stroke: the Northern Manhattan Study (NOMAS). Arch Neurol. 2009;66(11):1400-1406. doi:10.1001/ archneurol.2009.210 
15. Kurth T, Everett BM, Buring JE, Kase CS, Ridker PM, Gaziano JM. Lipid levels and the risk of ischemic stroke in women. Neurology. 2007;68(8):556-562. doi:10.1212/01.wnl.0000254472.41810.0d

16. Boden WE, Probstfield JL, Anderson T, et al. Niacin in patients with low HDL cholesterol levels receiving intensive statin therapy. $N$ Engl $J$ Med. 2011;365(24):2255-2267.

17. Landray MJ, Haynes R, Hopewell JC; Group HTC. et al. Effects of extended-release niacin with laropiprant in high-risk patients. $N$ Engl J Med. 2014;371(3):203-212.

18. Saito I, Yamagishi K, Kokubo Y, et al. Association of high-density lipoprotein cholesterol concentration with different types of stroke and coronary heart disease: the Japan Public Health Center-based prospective (JPHC) study. Atherosclerosis. 2017;265:147-154. doi:10.1016/j.atherosclerosis.2017.08.032

19. Soyama Y, Miura K, Morikawa Y, et al. High-density lipoprotein cholesterol and risk of stroke in Japanese men and women: the Oyabe Study. Stroke. 2003;34(4):863-868. doi:10.1161/01.STR.0000060869.34009.38

20. Tall AR. An overview of reverse cholesterol transport. Eur Heart J. 1998;19 Suppl A:A31-5.

21. Yoshikawa M, Sakuma N, Hibino T, Sato T, Fujinami T. HDL3 exerts more powerful anti-oxidative, protective effects against copper-catalyzed LDL oxidation than HDL2. Clin Biochem. 1997;30(3):221-225. doi:10.1016/S0009-9120(97)00031-3

22. Kontush A, Chantepie S, Chapman MJ. Small, dense HDL particles exert potent protection of atherogenic LDL against oxidative stress. Arterioscler Thromb Vasc Biol. 2003;23(10):1881-1888. doi:10.1161/ 01.ATV.0000091338.93223.E8

23. Ashby DT, Rye KA, Clay MA, Vadas MA, Gamble JR, Barter PJ. Factors influencing the ability of HDL to inhibit expression of vascular cell adhesion molecule-1 in endothelial cells. Arterioscler Thromb Vasc Biol. 1998;18(9):1450-1455. doi:10.1161/01.ATV.18.9.1450

24. Nordestgaard BG. Triglyceride-rich lipoproteins and atherosclerotic cardiovascular disease: new insights from epidemiology, genetics, and biology. Circ Res. 2016;118(4):547-563. doi:10.1161/ CIRCRESAHA.115.306249
25. Nordestgaard BG, Varbo A. Triglycerides and cardiovascular disease. Lancet. 2014;384(9943):626-635. doi:10.1016/S0140-6736(14)61177-6

26. Di Angelantonio E, Sarwar N, Perry P, et al.; Emerging Risk Factors C. Major lipids, apolipoproteins, and risk of vascular disease. JAMA. 2009;302(18):1993-2000. doi:10.1001/jama.2009.1619.

27. Ballantyne CM, Olsson AG, Cook TJ, Mercuri MF, Pedersen TR, Kjekshus J. Influence of low high-density lipoprotein cholesterol and elevated triglyceride on coronary heart disease events and response to simvastatin therapy in 4S. Circulation. 2001;104(25):3046-3051. doi: $10.1161 / \mathrm{hc} 5001.100624$

28. Manninen V, Tenkanen L, Koskinen P, et al. Joint effects of serum triglyceride and LDL cholesterol and HDL cholesterol concentrations on coronary heart disease risk in the Helsinki Heart Study. Implications for treatment. Circulation. 1992;85(1):37-45. doi:10.1161/01.CIR.85.1.37

29. Hokanson JE, Austin MA. Plasma triglyceride level is a risk factor for cardiovascular disease independent of high-density lipoprotein cholesterol level: a meta-analysis of population-based prospective studies. J Cardiovasc Risk. 1996;3(2):213-219. doi:10.1097/ 00043798-199604000-00014

30. Gotto AM. Interrelationship of triglycerides with lipoproteins and high-density lipoproteins. Am J Cardiol. 1990;66(6):A20-A3. doi:10.1016/0002-9149(90)90565-I

31. Tedla YG, Yano Y, Carnethon M, Greenland P. Association between long-term blood pressure variability and 10-year progression in arterial stiffness. Hypertension. 2017;69(1):118-127. doi:10.1161/ HYPERTENSIONAHA.116.08427

32. Wannamethee SG, Shaper AG, Ebrahim S. HDL-cholesterol, total cholesterol, and the risk of stroke in middle-aged British men. Stroke. 2000;31(8):1882-1888. doi:10.1161/01.STR.31.8.1882
Clinical Interventions in Aging

\section{Publish your work in this journal}

Clinical Interventions in Aging is an international, peer-reviewed journal focusing on evidence-based reports on the value or lack thereof of treatments intended to prevent or delay the onset of maladaptive correlates of aging in human beings. This journal is indexed on PubMed Central, MedLine, CAS, Scopus and the Elsevier

\section{Dovepress}

Bibliographic databases. The manuscript management system is completely online and includes a very quick and fair peer-review system, which is all easy to use. Visit http://www.dovepress.com/ testimonials.php to read real quotes from published authors. 